\title{
Arsitektur Neo Vernakular sebagai Salah Satu Aspek Penunjang Pelestarian Kebudayaan Lamaholot
}

\author{
Anastasia Eka S.T.H. ${ }^{1}$, Sigit Hadi Laksono ${ }^{2}$, Wiwik Widyo Widjajanti ${ }^{3}$ \\ 1,2,3Jurusan Arsitektur, Fakultas Teknik Sipil dan Perencanaan, Institut Teknologi Adhi Tama Surabaya \\ Email: ${ }^{1}$ aekahalimalimaking@gmail.com, ${ }^{2}$ sigitarci@gmail.com, ${ }^{3}$ wiwikwidyo@yahoo.com
}

\begin{abstract}
In this growing era, there are many aspects in the order of life that begin to change, disappear or be forgotten, one of which is culture, which is the identity and pride of every ethnic group in the world. Lamaholot is one of the ethnic groups in the culture of East Nusa Tenggara, which is starting to experience shock and cultural shifts, especially in Lembata district. From this problem, Neo Vernacular is felt to have a big role to support the sustainability of Lamaholot culture, especially in the architectural field, it can be implemented in physical form (form, construction) and non-physical (concept, philosophy, spatial layout) in Planning and Design projects. Lamaholot Cultural Education Center in Nubatuan, Lembata Regency, East Nusa Tenggara. The role of Neo Vernacular Architecture is to pack Lamaholot culture into an architectural form that can be seen, enjoyed and used well, without having to leave the normative rules that applied. Lamaholot local architectural principles applicated in the form of composition and land layout pattern that has a gathering area in the middle or "namang" in the so-called traditional village, the application of roof roof "kote mane" on all buildings in the design and the application of cultural aspects such as woven fabric motifs embodied as ornaments and decorations on shape on the plan. The study method used was qualitative with the data processing stage through the process of grouping and structuring both the results of literature theory studies, literature, field surveys, and observations according to predetermined categories and classifications, continued with the data analysis and designing process.
\end{abstract}

Keywords: Culture, Lamaholot, Neo Vernacular.

\begin{abstract}
Abstrak. Di zaman yang terus berkembang ini, ada banyak aspek dalam tatanan kehidupan yang mulai berubah, hilang ataupun terlupakan, salah satunya adalah kebudayaan, yang merupakan identitas dan kebanggaan bagi setiap suku bangsa di dunia. Lamaholot merupakan salah satu suku dalam kebudayaan yang ada di Nusa Tenggara Timur, yang mulai mengalami kekagetan dan pergeseran budaya, terkhusus yang berada di kabupaten Lembata. Dari permasalahan itu Neo Vernakular dirasa memiliki peran yang besar guna mendukung keberlangsungan pelestarian kebudayaan Lamaholot, khususnya bidang arsitektural, hal tersebut dapat diimplementasikan kedalam bentuk fisik (bentuk, konstruksi) maupun non fisik (konsep, filosofi, tata ruang) dalam proyek Perencanaan dan Perancangan Pusat Edukasi Kebudayaan Lamaholot di Nubatukan, Kabupaten Lembata, Nusa Tenggara Timur. Peran Arsitektur Neo Vernakular yaitu mengemas kebudayaan Lamaholot ke dalam bentuk arsitektural yang dapat dilihat, dinikmati dan digunakan dengan baik, tanpa harus meninggalkan kaidah-kaidah normative yang berlaku. Prinsipprinsip arsitektur lokal Lamaholot yang diterapkan berupa penggubahan dan pola tatanan lahan yang memiliki area kumpul pada bagian tengahnya atau "namang” dalam peyebutan kampung adat, penerapan bumbungan atap "kote mane” pada seluruh bangunan yang ada pada rancangan serta pengaplikasian aspek-aspek kebudayaan seperti motif kain tenun yang diwujudkan menjadi ornamen dan dekorasi pada bentuk dan ruang pada rancangan. Metode kajian yang digunakan yaitu kualitatif dengan tahap pengolahan data yang melalui proses pengelompokkan dan penstrukturan baik hasil dari studi teori pustaka, literatur, survei lapangan, dan observasi sesuai kategori dan klasifikasi yang dilanjutkan dengan analisa data dan perancangan.
\end{abstract}

Kata Kunci: Kebudayaan, Lamaholot, Neo Vernakular.

\section{Pendahuluan}

Di Indonesia, Nusa Tenggara Timur merupakan salah satu provinsi yang menjunjung tinggi kebudayaannya, salah satunya adalah kebudayaan suku Lamaholot yang mendiami bagian timur Pulau 
Flores, Pulau Adonara, Pulau Lembata, Pulau Solor, serta Pulau Alor. Dari kelima pulau tersebut, pulau Lembata merupakan kabupaten yang terbilang masih baru dan dirasa membawa dampak yang besar dalam upaya pengenalan dan pelestarian kebudayaan Lamaholot, selain pertimbangan tersebut, adanya isu kekagetan budaya (culture shock) atau memudarnya nilai-nilai budaya dikalangan masyarakat Lembata, adanya visi dan misi rencana Rehabilitasi dan Pembangunan balai budaya di kecamatan Nubatukan dalam Rencana Pembangunan Jangka Menengah Daerah (RPJMD) periode 2017-2022 kabupaten Lembata, serta adanya kenaikan grafik kunjungan wisatawan dari tahun 2013 - 2016 yang mencapai jumlah 6.921 dirasa memiliki peluang yang besar untuk menjadi pilihan destinasi wisata budaya yang dapat menarik minat wisatawan lokal maupun wisatawan asing yang datang ke pulau Lembata.

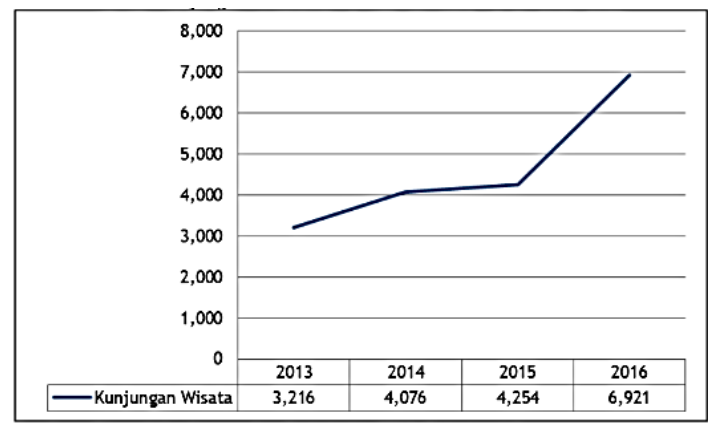

Gambar 1. Grafik Jumlah Kunjungan Wisata di Kab.Lembata Tahun 2013 - 2016

Sumber : Dinas Kebudayaan dan Pariwisata 2016, Data terolah Bappelitbangda Tahun 2017

Pertimbangan-pertimbangan di atas membawa dampak besar yang dapat mendukung proyek rancangan kali ini, terkhusus proses pengenalan, pembelajaran dan pelestarian kebudayaan Lamaholot di Lembata, yang diharapkan dapat menjadi kompleks pusat edukasi dengan fasilitas-fasilitas yang diperlukan guna mendukung kegiatan-kegiatan yang akan dilaksakan disana. Adapun pertimbangan permasalahan umum yang akan diusung dan menjadi pertimbangan dalam proyek rancangan ini adalah bagaimana cara menciptakan rancangan Pusat Edukasi Kebudayaan Lamaholot sekaligus destinasi wisata budaya yang dapat menjadi wadah pengenalan, pembelajaran serta pelestarian kebudayaan yang menarik bagi warga setempat maupun wisatawan namun tetap mempertahankan kaidah kebudayaan Lamaholot tapi juga terkesan dinamis dan dapat dinikmati oleh semua kalangan masyarakat untuk semua usia.

\section{Kajian Teori}

Neo berasal dari bahasa Yunani dan digunakan sebagai fonim yang berarti baru. Jadi Neo Vernakular berarti bahasa setempat yang diucapkan dengan cara baru, arsitektur Neo Vernakular adalah suatu penerapan elemen arsitektur yang telah ada, baik fisik (bentuk, konstruksi) maupunnon fisik (konsep, filosofi tata ruang) dengan tujuan melestarikan unsur-unsur lokal yang telah terbentuk secara empiris oleh sebuah tradisi yang kemudian sedikit atau banyaknya mengalami pembaruan menuju suatu karya yang lebih modern atau maju tanpa mengesampingkan nilai-nilai tradisi setempat (Putra, 2013).

Kebudayaan $=$ cultuur (bahasa Belanda), culture (bahasa Inggris) berasal dari bahasa Latin corele yang berarti mengolah, mengerjakan, menyuburkan, dan mengembangkan, terutama mengolah tanah atau bertani. Bertolak dari arti tersebut, kemudian kata culture ini berkembang pengetiannya menjadi "segala daya dan aktivitas manusia untuk mengolah dan mengubah alam" (Djoko Widagdho, 1991).

Lamaholot (atau Lamakolot, Lamholot, Solor, Larantuka) adalah salah satu suku bangsa yang berdiam di dalam wilayah Kabupaten Flores Timur, Provinsi Nusa Tenggara Timur, Indonesia. Suku Lamaholot mendiami sebagian besar wilayah kabupaten tersebut, yang meliputi bagian timur Pulau Flores, Pulau Adonara, Pulau Lembata, Pulau Solor, dan Pulau Alor. Dalam kabupaten ini mereka hidup berdampingan dengan kelompok-kelompok lain, seperti orang Kedang, orang Lalaba, bersama dengan kelompok pendatang seperti Bugis, Makassar, Buton, serta keturunan Cina. 
Kabupaten tempat Suku Lamaholot berdiam ini merupakan wilayah kepulauan vulkanis dengan rangkaian bukit-bukit dengan sejumlah gunung berapi yang masih aktif, yaitu Gunung Lewotobi lakilaki, Gunung Lewotobi Perempuan, Gunung Leraboleng dan Gunung Liboleng. Letak geografis wilayah kabupaten ini berdampak pada klimatologi yaitu mengalami dua musim seperti daerahdaerah lain di Indonesia yaitu musim kemarau dan musim hujan. Adapun pemanfaatan lahan berupa tanah sawah, tanah pekarangan, tanah tegalan, hutan, perkebunan, perikanan, peternakan dengan sumber mata air umumnya berada pada kawasan hutan.

\section{Metode Penelitian}

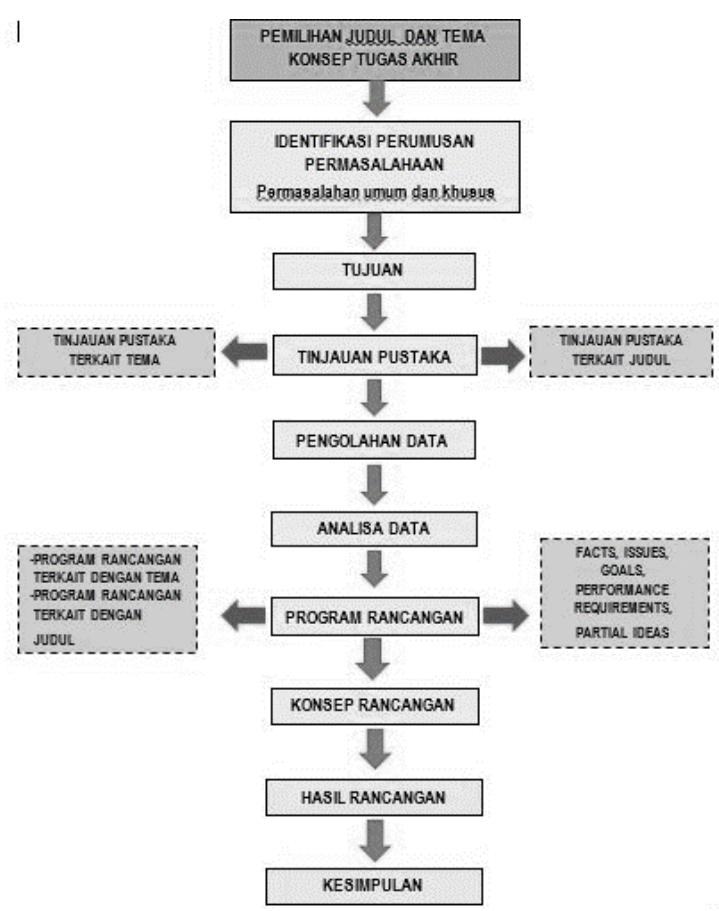

Gambar 2. Diagram Alur Penelitian

Pada proyek rancangan ini metode penelitian yang digunakan adalah kualitatif yang sifatnya memberikan penjelasan dengan menggunakan analisis. Pada pelaksanaannya, metode ini bersifat subjektif dimana proses penelitian lebih tiperlihatkan dan cenderung lebih fokus pada landasan teori. Metode riset ini juga disebut dengan metode etnografi karena sangat jamak dipakai untuk melakukan pengamatan kondisi sosial budaya. Sedangkan sumber data penelitian dapat diperoleh melalui dua data, yaitu data primer dan sekunder serta teknik pengumpulan data yang digunakan berupa metode Observasi, interview, dokumentasi dan literatur.

Pada tahap pengolahan data, hasil identifikasi temuan data penelitian secara lengkap selanjutnya akan diolah dengan proses pengelompokkan dan penstrukturan seluruh temuan data, baik hasil dari studi teori pustaka, literatur, survei lapangan, dan observasi sesuai kategori dan klasifikasi yang telah ditentukan. Data yang telah diorganisasikan kemudian dilakukan suatu proses pengurutan data, dan dilakukan suatu uraian untuk menjelaskan informasi data-data yang dibutuhkan untuk tahap analisis, baik diuraikan dalam bentuk penjelasan kalimat, gambar, maupun tabulasi sesuai dengan pengelompokan data yang telah dilakukan sebelumnya. Hasil identifikasi temuan data penelitian secara lengkap selanjutnya akan diolah dengan proses pengelompokkan dan penstrukturan seluruh temuan data, baik hasil dari studi teori pustaka, literatur, survei lapangan, dan observasi sesuai kategori dan klasifikasi yang telah ditentukan. Data yang telah diorganisasikan kemudian dilakukan suatu proses pengurutan data, dan dilakukan suatu uraian untuk menjelaskan informasi data-data yang dibutuhkan untuk tahap analisis, baik diuraikan dalam bentuk penjelasan kalimat, gambar, maupun tabulasi sesuai dengan pengelompokan data yang telah dilakukan sebelumnya. 
Sedangkan tahap analisa data merupakan proses penyusunan kajian analisis dan pembahasan terhadap hasil identifikasi temuan data penelitian dengan pendekatan pada sintesis teori-teori pustaka, data literatur, dan peraturan pemerintah maupun arahan kebijakan kawasan. Kajian analisis dilakukan dengan metode kualitatif deskriptif, baik disajikan secara tertulis maupun gambar. Adapun dalam hal analisa, data yang didapat dianalisa menggunakan metode analisa sebagai berikut (a) Metode Kualitatif (b) Metode Induktif. Dan setelah semua tahap analisa data dilakukan dan memperoleh kesimpulan maka proses awal merancang dapat dilakukan, yaitu penyusunan program rancang, dan dilanjutkan dengan tahap-tahap selanjutnya.

\section{Analisis dan Pembahasan}

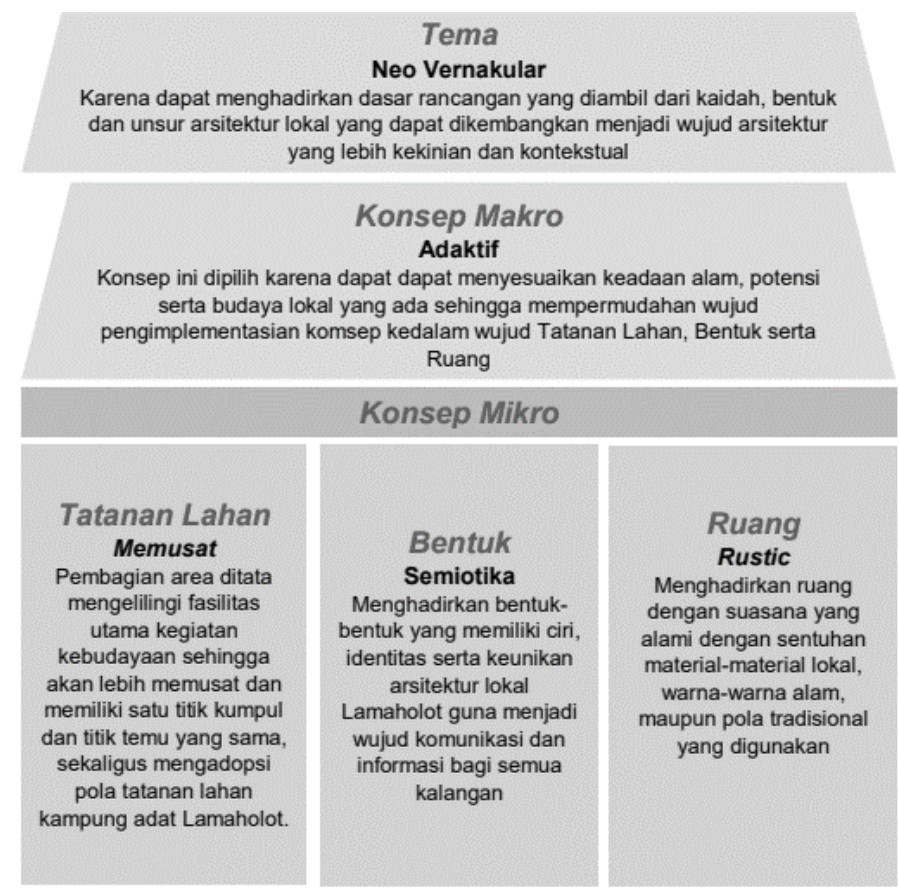

Gambar 3. Bagan Konsep Rancangan

Untuk tatanan tapak konsep "Memusat" dipilih dan disesuaikan dengan judul serta kaidah tatanan kampung adat Lamaholot yaitu memiliki titik tengah atau pusat (Namang) yang menjadi titik temu semua bangunan yang digunakan sebagai area berkumpul serta ruang publik. Adapun penerapan konsep mikro tatanan lahan "memusat" adalah sebagai berikut (a) Semua bangunan pada rancangan ini menghadap kearah pusat tapak (b) Sirkulasi yang diterapkan bersifat terarah, berbentuk melingkar dan mengelilingi tapak, sehingga seluruh area yang ada dapat dikunjungi secara maksimal (c) Pola Tatanan lahan yang dirancang memiliki pola dasar yang diadopsi dari motif lokal Lamaholot dengan perpaduan elemen hardscape dan softscape yang seimbang.

Konsep mikro bentuk yang diusung "Semiotika" merupakan konsep yang dibentuk dari pengkajian tanda (symbol, indeks dan ikon). Pada rancangan ini semiotika dipilih karena dirasa memiliki kesesuaian dengan tema neo vernakular yang sama-sama terjadi di era post modern serta dapat menciptakan bentuk-bentuk yang ikonik dan memiliki ciri khusus. Adapun penerapan konsep mikro bentuk "semiotika" adalah sebagai berikut (a) Menghadirkan bentuk yang ikonik monumental dengan sentuhan arsitektur lokla yang dikemas secara lebih kekinian. (b) penggubahan bentuk bangunan pada rancangan ini pada prinsipnya megambil kaidah dan ciri yang ada pada rumah adat Lamaholot yaitu memiliki simbol pada bagian atap (kote) yang berfungsi sebagai penangkal bala dan untuk menandai rumah adat tersebut sudah direnovasi atau belum. (c) Ornamen ataupun dekorasi yang ada pada bangunan diambil dari motif kain tenun ikat Lembata. 


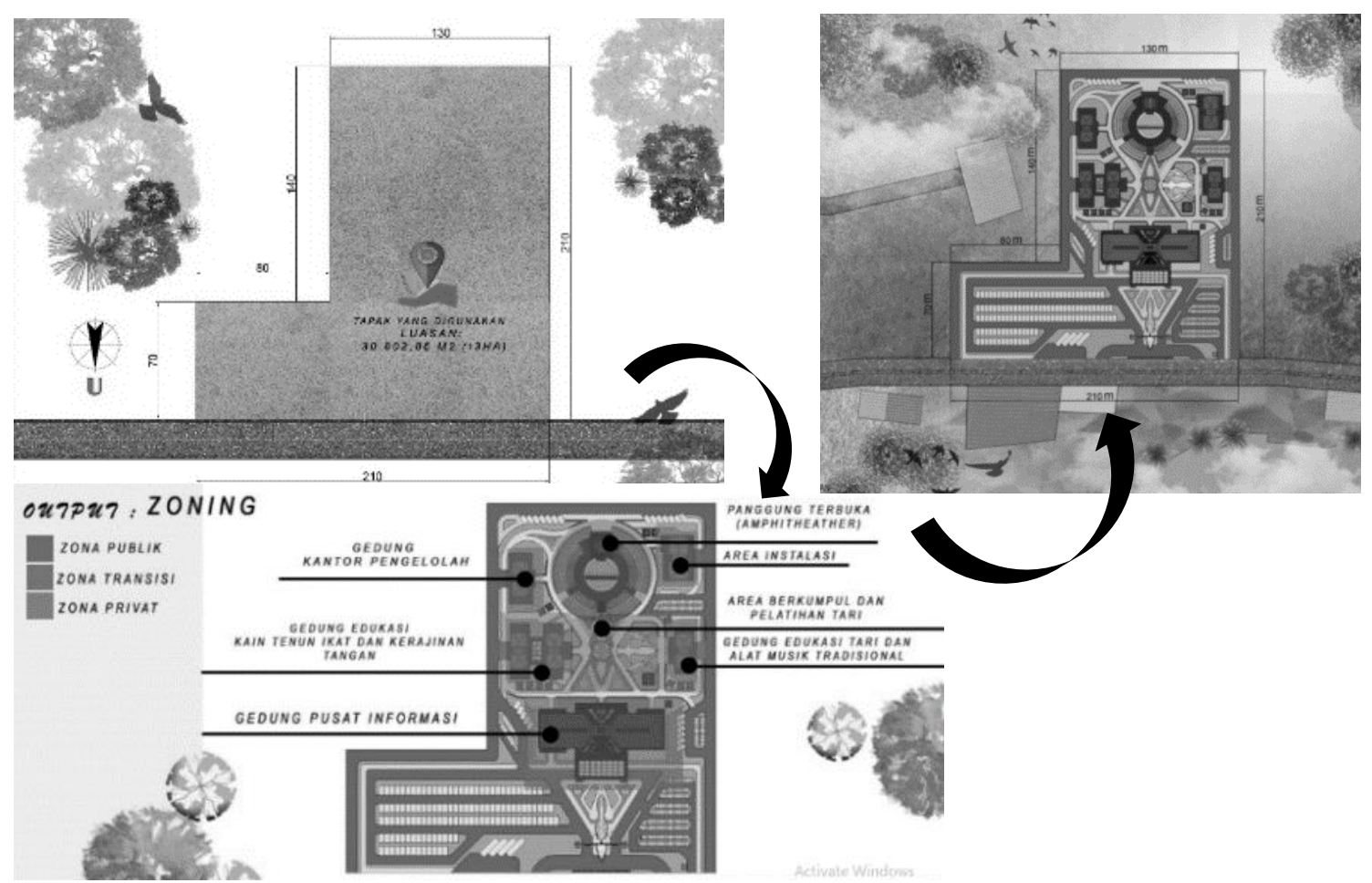

Gambar 4. Transformasi Tatanan Lahan

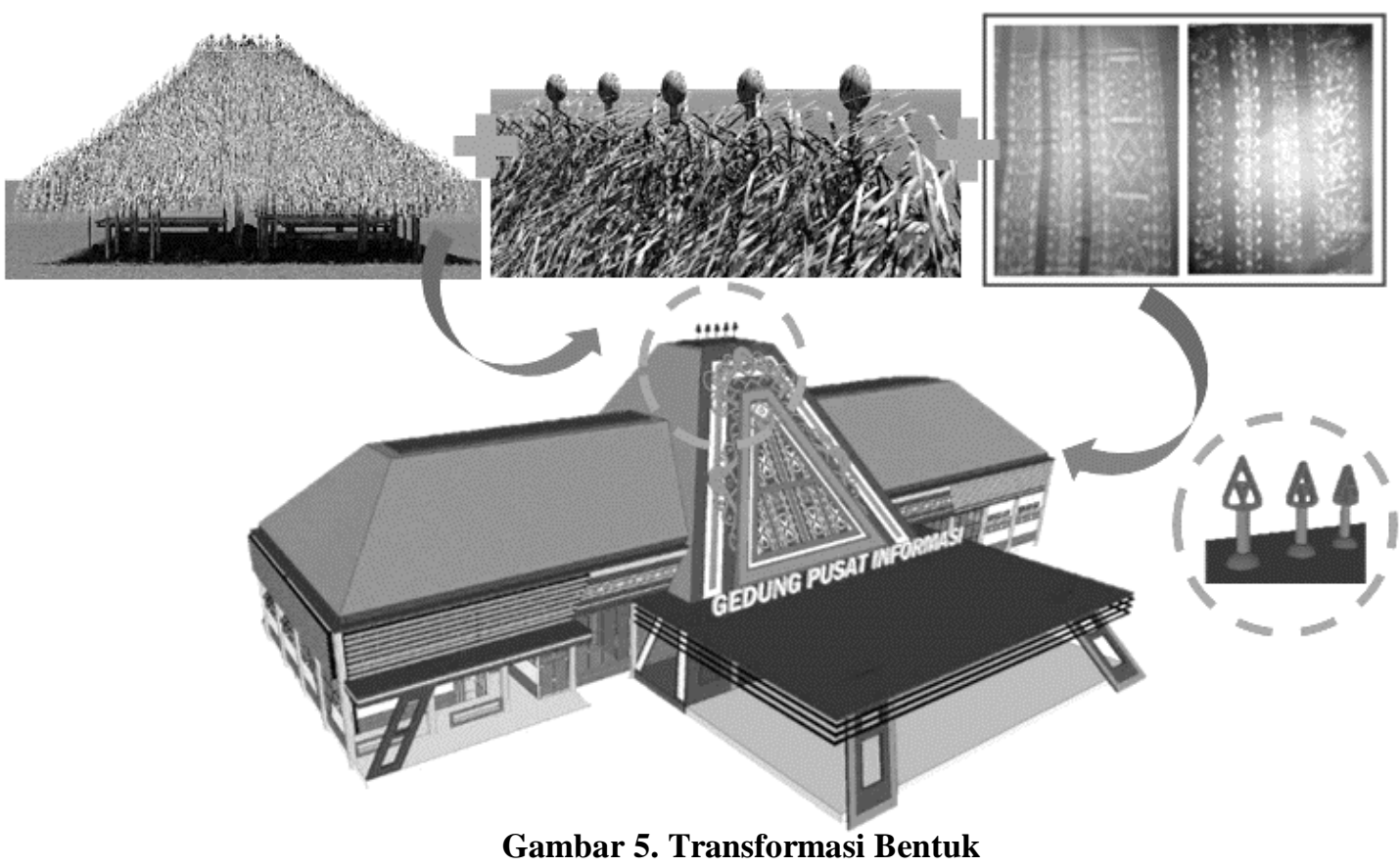

Konsep ruang yang diusung adalah Konsep "Rustic" yang memiliki tekstur tidak halus (kasar), tidak terselesaikan, dan memiliki kesan yang alamiah dipilih karena pada dasarnya konsep ini telah lama diterapkan di Indonesia terutama pada bangunan yang menerapkan gaya tradisional. Selain itu, konsep ini juga memiliki kesesuaian dengan tema neo vernakular yang diusung sehingga dapat saling berkesinambungan. Adapun penerapan konsep mikro runag "rustic" adalah sebagai berikut (a) Menggunakan material lokal dan alami seperti kayu, batu alam (b) Menggunakan warna-warna alam seperti coklat, orange, hitam (c) Menggunakan pola yang terkesan tradisional dengan sentuhan motif 
kain tenun ikat dengan dekorasi sentuhan etnik yang disandingkan dengan material kayu sehingga memberikan kesan yang kuno.

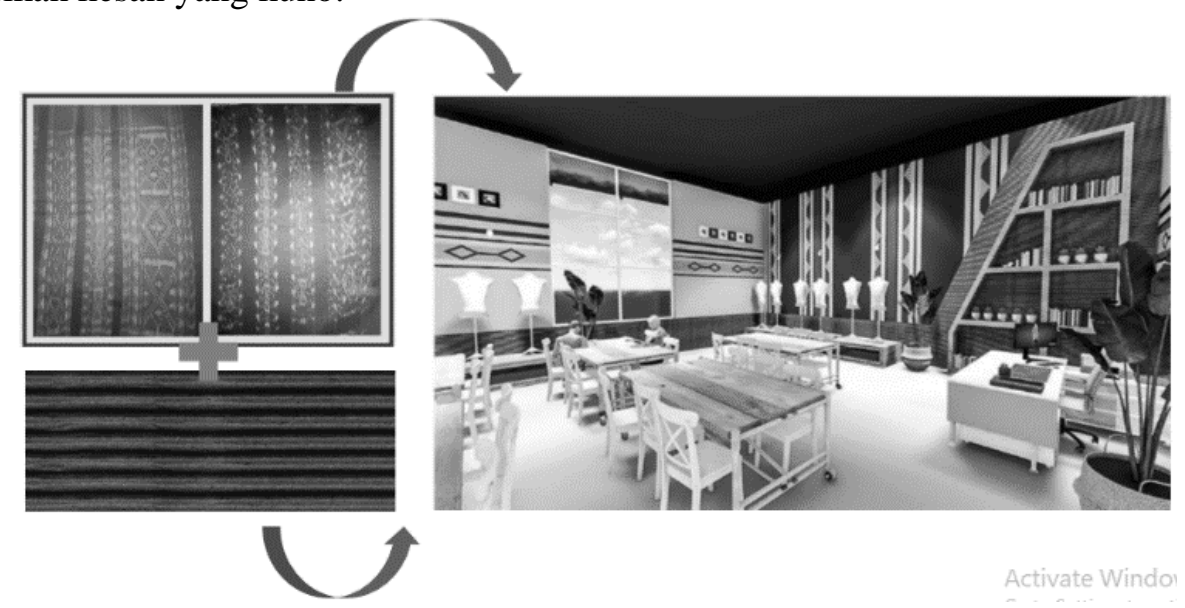

Gambar 6. Transformasi Ruang

\section{Kesimpulan}

Dari penjelasan diatas, dapat diketahui bahwa arsitektur Neo Vernakular memiliki peran penting dalam mewujudkan wajah kebudayaan Lamaholot kedalam bentuk rancangan arsitektural yang dapat dinikmati secara fisik maupun non fisik, sehingga kebudayaan Lamaholot tidak hanya dihayati secara jiwa dan sosial tetapi juga dapat menjadi wadah pengenalan, pembelajaran serta pelestarian kebudayaan yang menarik namun tetap mempertahankan kaidah kebudayaan Lamaholot tetapi juga terkesan dinamis dan dapat dinikmati oleh semua kalangan masyarakat untuk semua usia baik warga setempat maupun wisatawan.

\section{Referensi}

Widagdho, D. (1999). In Drs.Sujarwa, Manusia dan Fenomena Budaya Menuju Prespektif Moralitas Agama (p. 7). Yogyakarta: Universitas Ahmad Dahlan Yogyakarta bekerja sama dengan Pustaka Belajar.

Putra, Tjok Pradnya. (2013). Pegertian Arsitektur Vernakular [Diakses dari: https://www.scribd.com/doc/135985062/Pengertian-Arsitektur-Neo-Vernakular]

(https://lembatakab.bps.go.id/, n.d.)

(https://kbbi.web.id/biro, n.d.)

(Google earth, n.d.)

(Pemerintah Kabupaten Lembata Nusa Tenggara Timur, n.d.) 